Erratum

\title{
Erratum to "Some Additions to the Fuzzy Convergent and Fuzzy Bounded Sequence Spaces of Fuzzy Numbers"
}

\author{
M. Şengönül and Z. Zararsız \\ Science and Art Faculty, Nevşehir University, 50300 Nevşehir, Turkey \\ Correspondence should be addressed to M. Şengönül; msengonul@yahoo.com \\ Received 7 June 2013; Accepted 20 October 2013; Published 16 January 2014 \\ Copyright (c) 2014 M. Şengönül and Z. Zararsız. This is an open access article distributed under the Creative Commons Attribution \\ License, which permits unrestricted use, distribution, and reproduction in any medium, provided the original work is properly \\ cited.
}

In page 4 , line 8 from the bottom " ... if for any given $\epsilon<0$, there exists an integer $n_{0} \ldots$ ". is changed to "... if for any given $0<\epsilon \in G$, there exists an integer $n_{0} \ldots . . "$

The "Hereafter $\epsilon$ will be considered the smallest positive fuzzy number." must be added to the end of line 6, from bottom, in page 4 . 


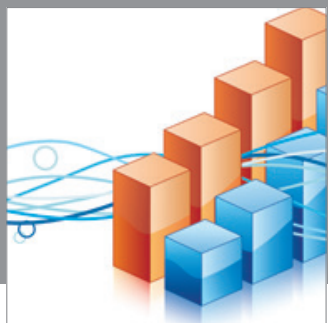

Advances in

Operations Research

mansans

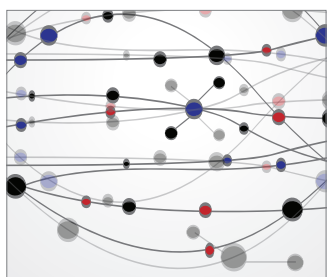

The Scientific World Journal
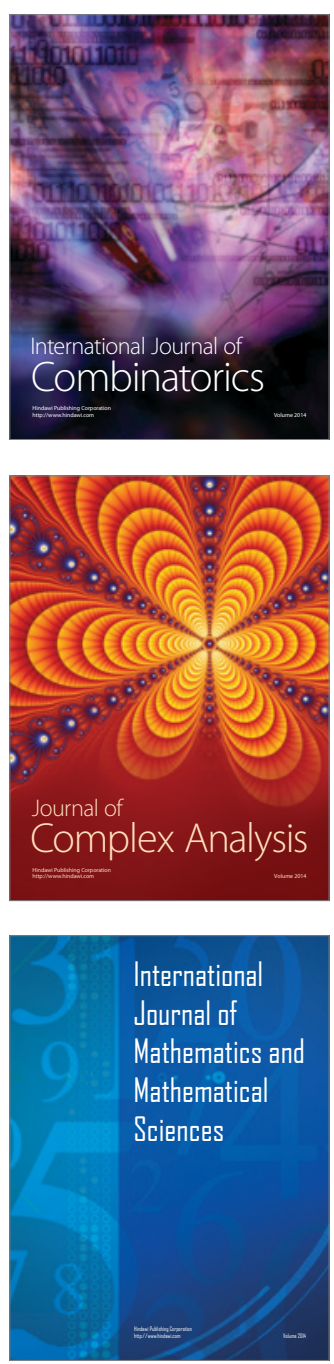
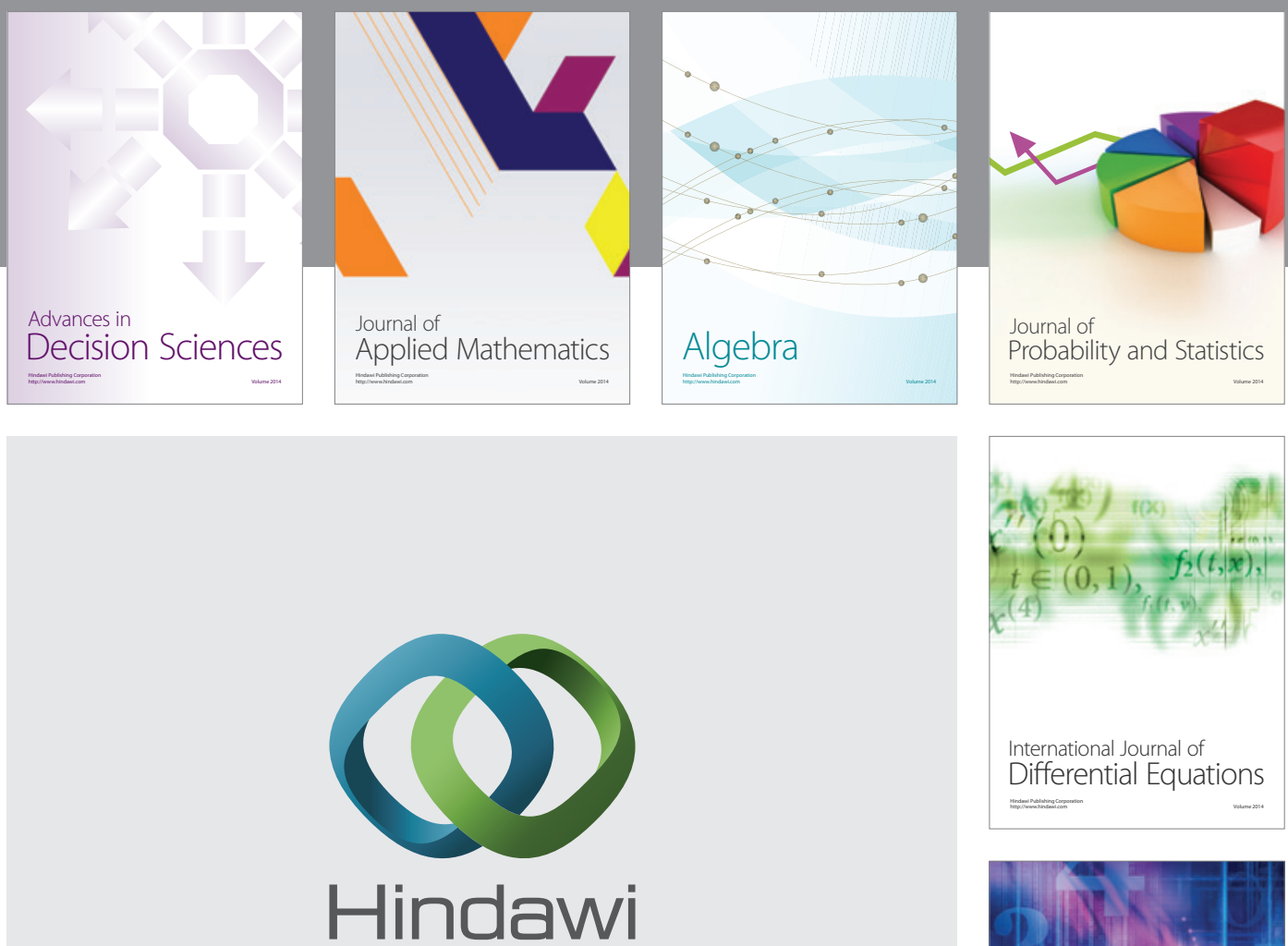

Submit your manuscripts at http://www.hindawi.com
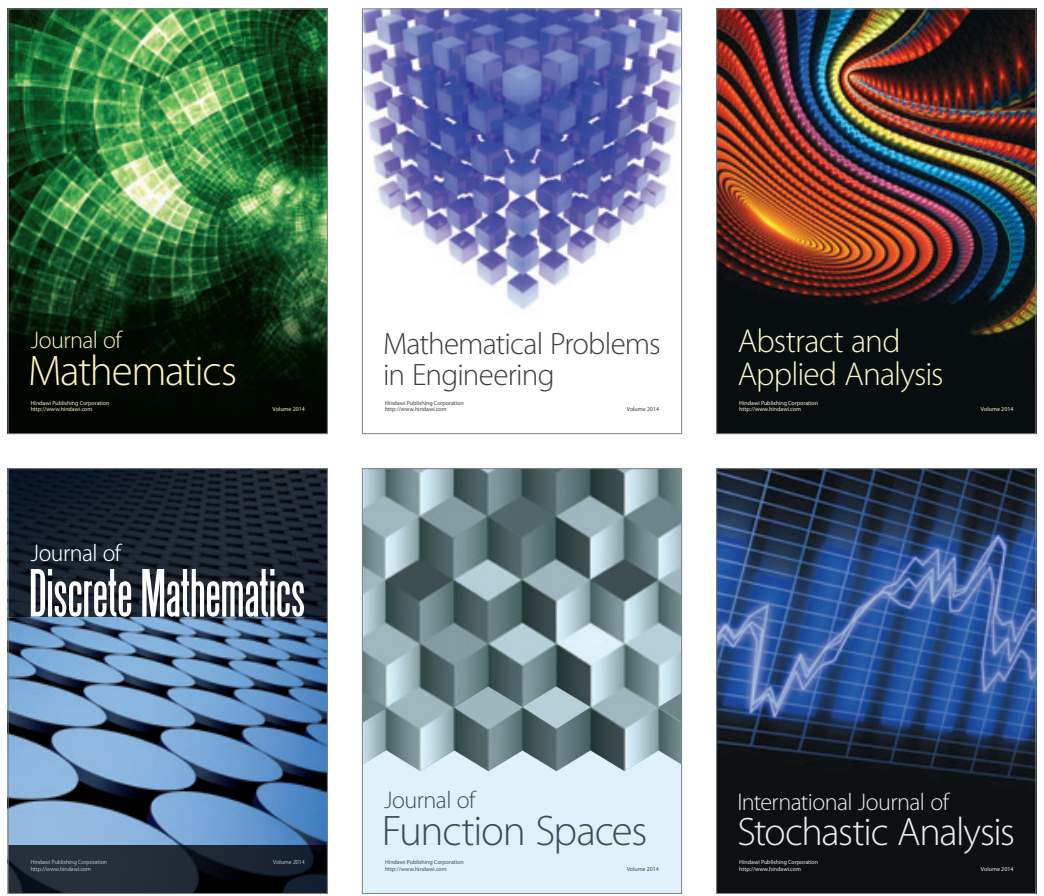

Journal of

Function Spaces

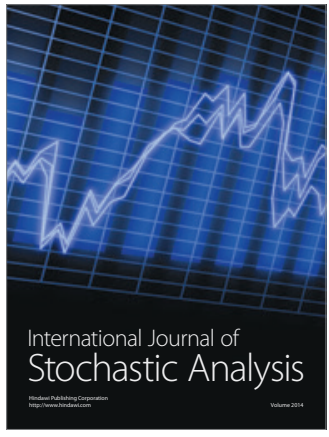

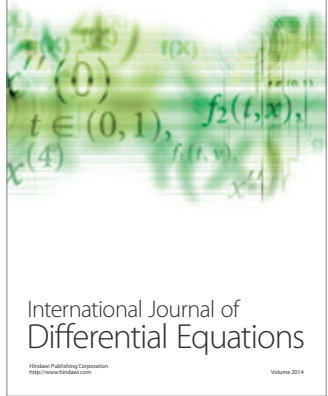
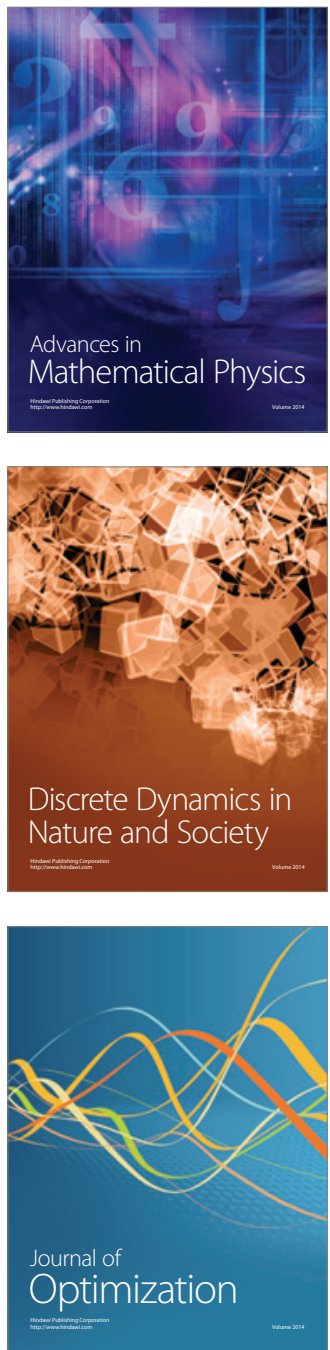